\title{
Produtividade de salsa cultivada em sistema hidropônico e semi- hidropônico, no município de Paragominas/Pará
}

A salsa é uma cultura que pode ser cultivada em sistema hidropônico, semi-hidropônico e solo, apresenta destaque por sua capacidade de rebrotamento, que pode ser explorado por dois a três anos. Com isso, o objetivo desta pesquisa foi avaliar a produtividade e o teor clorofila da salsa em cultivo hidropônico e semihidropônico em duas colheitas, no município de Paragominas-Pará. O experimento foi conduzido na propriedade B\&A Hidroponia. O delineamento utilizado foi o inteiramente casualizado em esquema fatorial 2×2, sendo dois sistemas (hidropônico e semi-hidropônico) e duas colheitas, com seis repetições. Em campo fo avaliada a clorofila, utilizando aparelho chamado ClorofiLOG-CFL1030. Em laboratório foi avaliado os parâmetros: número de folhas, peso de massa fresca e seca (g), largura $(\mathrm{mm})$, comprimento $(\mathrm{mm})$ e dados para o auxílio do cálculo de área foliar $\left(\mathrm{mm}^{2}\right)$ e produtividade (g planta-1). Os dados obtidos foram submetidos à análise de variância, e as médias comparadas pelo teste de Tukey a $5 \%$ de probabilidade. Em termos de produtividade, a salsa apresenta melhor resultado no sistema semi-hidropônico se colhido após a rebrotação, ou seja, segunda colheita. Se o cultivo for em hidroponia, a maior produtividade se dará na primeira colheita. No geral, a salsa hidropônica apresentou melhores resultados, quando comparado ao sistema de cultivo no semi-hidropônico, na maior parte dos parâmetros analisados. A clorofila (A, B e Total) no sistema semi hidropônico foi superior se comparado com sistema hidropônico, com melhor média para a segunda colheita.

Palavras-chave: Clorofila; Hortaliça; Rebrota; Sistemas de cultivo.

\section{Productivity of parsley grown in a hydroponic and semi-hydroponic system, in the municipality of Paragominas/Pará}

\begin{abstract}
Parsley is a crop that can be grown in a hydroponic, semi-hydroponic and soil system, it stands out for its ability to sprout, which can be explored for two to three years. Thus, the objective of this research was to evaluate the productivity and chlorophyll content of parsley in hydroponic and semi-hydroponic cultivation in two harvests, in the municipality of Paragominas-Pará. The experiment was conducted at the B\&A Hydroponics property. The design used was completely randomized in a $2 \times 2$ factorial scheme, with two systems (hydroponic and semi-hydroponic) and two harvests, with six replications. In the field, chlorophyll was evaluated using a device called ChlorofiLOG-CFL1030. In the laboratory, the parameters were evaluated: number of leaves, weight of fresh and dry mass ( $g$ ), width $(\mathrm{mm})$, length $(\mathrm{mm})$ and data to aid the calculation of leaf area $\left(\mathrm{mm}^{2}\right)$ and productivity (g plant-1). The data obtained were subjected to analysis of variance, and the means compared by the Tukey test at $5 \%$ probability. In terms of productivity, parsley shows better results in the semi-hydroponic system if harvested after regrowth, that is, the second harvest. If the cultivation is in hydroponics, the highest productivity will occur in the first harvest. In general, the hydroponic parsley showed better results, when compared to the cultivation system in the semi-hydroponic, in most of the analyzed parameters. Chlorophyll (A, B and Total) in the semi-hydroponic system was superior compared to the hydroponic system, with a better average for the second harvest.
\end{abstract}

Keywords: Chlorophyll; Regrowth; Vegetable; Cultivation Systems.

Aline Bittencourt Nunes (ID)

Universidade Federal Rural da Amazônia, Brasil http://lattes.cnpq.br/3797454209447522 http://orcid.org/0000-0003-3356-8340 alinebittencourtnunes@gmail.com

Rhaiana Oliveira de Aviz

Universidade Federal Rural de Pernambuco, Brasil http://lattes.cnpq.br/2715037307668915 http://orcid.org/0000-0002-4462-4339 rhaianaoliveiradeaviz@gmail.com

Luana Keslley Nascimento Casais (it) Universidade Federal Rural da Amazônia, Brasil http://lattes.cnpq.br/8075409193627849 http://orcid.org/0000-0001-7197-5524 luana.casais@gmail.com

\author{
Thaís Vitória dos Santos (iD \\ Universidade Federal Rural da Amazônia, Brasi \\ http://lattes.cnpq.br/1924823584014410 \\ http://orcid.org/0000-0002-6620-575X \\ thaisvitoria104@gmail.com \\ Denilze Santos Soares \\ Universidade Federal Rural da Amazônia, Brasil \\ http://lattes.cnpq.br/0560995243358445 \\ http://orcid.org/0000-0001-9121-6234 \\ denilzesoares@gmail.com \\ Gustavo Antonio Ruffeil Alves (id \\ Universidade Federal Rural da Amazônia, Brasil \\ http://lattes.cnpq.br/1638279411609759 \\ http://orcid.org/0000-0003-2802-2036 \\ gustavo.ruffeil@ufra.edu.br
}

Luís de Souza Freitas (iD

Universidade Federal Rural da Amazônia, Brasil http://lattes.cnpq.br/0747504282703764 http://orcid.org/0000-0003-2321-5269 luisufra@gmail.com

\section{Luciana da Silva Borges (iD)}

Universidade Federal Rural da Amazônia, Brasi http://lattes.cnpq.br/45337222536181534 http://orcid.org/0000-0002-1194-6411 luciana.borges@ufra.edu.br
DOI: 10.6008/CBPC2179-6858.2020.006.0045
Referencing this:

NUNES, A. B.; AVIZ, R. O.; CASAIS, L. K. N.; SANTOS, T. V.; SOARES, D. S.; ALVES, G. A. R.; FREITAS, L. S.; BORGES, L. S.. Produtividade de salsa cultivada em sistema hidropônico e semi-hidropônico, no município de Paragominas/Pará. Revista Ibero Americana de Ciências Ambientais, v.11, n.6, p.559-567, 2020. DOI: http://doi.org/10.6008/CBPC2179-6858.2020.006.0045 


\section{INTRODUÇÃO}

A produção agrícola mundial de hortaliças cultivadas é cada vez mais crescente, de acordo com um levantamento de dados realizados em 2018, o Brasil apresenta posição de destaque neste setor, como um dos maiores produtores de frutas e olerícolas, apresentando uma produção média anual de 37 milhões de toneladas, dos quais, 3\% a 5\% são destinados para a exportação (BRONDANI, 2018).

Dentre as olerícolas, a salsa (Petroselinum crispum L.), merece destaque, não pelo seu volume de produção ou dados de comercialização, mas por ser um dos vegetais aromáticos mais populares da gastronomia mundial, bastante apreciada no preparo de várias iguarias da culinária brasileira, além de sua importância medicinal e socioeconômica (SABINO, 2010; HOEPERS, 2017).

É uma cultura que pode ser cultivada em sistema hidropônico, semi-hidropônico e solo, sua primeira colheita ocorre geralmente entre 55 dias após a semeadura (MARTINS et al., 2019), e possui a capacidade de rebrotamento, podendo um cultivo ser explorado por dois a três anos (COSTA, 2017).

Mundialmente, o cultivo hidropônico tornou-se um meio de produção bastante difundido, por apresentar características como melhor viabilização da produção, possibilitar a disponibilidade dos produtos na época da entressafra, garantindo assim uma regularidade de oferta, além de inserir um valor agregado ao produto final (ZEN et al., 2019).

Já sistema de cultivo comumente chamado de semi-hidropônico é aquele em que os métodos de cultivo são baseados na ausência do uso direto do solo, porém, utilizando algum tipo de material sólido de origem orgânica como meio para o crescimento das raízes, se destaca nos termos econômicos, por ser mais viável que o sistema hidropônico.

Todavia, poucos são os estudos acerca do cultivo hidropônico e semi-hidropônico da referida espécie, logo, o objetivo desta pesquisa foi avaliar a produtividade e o teor clorofila da salsa em cultivo hidropônico e semi-hidropônico em duas colheitas, no município de Paragominas-Pará.

\section{MATERIAIS E MÉTODOS}

O presente estudo foi conduzido em uma área situada nas intermediações da região do município de Paragominas, localizada ao sudeste paraense. A área de estudo, está localizada no Condomínio Rural, PA$256, \mathrm{Km} 05$, e é de posses da empresa B\&A Hidroponia ( $\left.3^{\circ} 0^{\prime} 18.09^{\prime \prime} \mathrm{S} 47^{\circ} 24^{\prime} 46.25^{\prime \prime} \mathrm{O}\right)$.

De acordo com a classificação climática de Köppen, a microrregião de Paragominas apresenta um clima quente e úmido do tipo Awi, com média anual em torno de 1800 mm de chuva, há uma estação chuvosa de fevereiro a maio, estiagem em junho, relativamente seca de julho a novembro e uma temporalidade em transição de dezembro a janeiro. A temperatura média anual gira em torno de 26,3ำ (FAPESPA, 2016).

A empresa vem trabalhando no ramo olerícola desde julho de 2016, principalmente com o cultivo de alface, jambu, rúcula, agrião, coentro e salsa, sendo o último o alvo desta pesquisa. Ao longo dos anos, além do cultivo hidropônico e solo, houve uma inserção da produção semi-hidropônica.

No geral, a parte estrutural é composta por estufas, sendo estas cobertas e com as laterais 
totalmente fechadas, uma casa de motor-bomba, onde estão inseridas as estruturas de bombeamento, controle e solução nutritiva e canteiros.

Nas estufas e canteiros, a temperatura média equivale a aproximadamente $30 \circ \mathrm{C}$ e 35 으, respectivamente, os sistemas são gerenciados por timer, mantendo a solução nutritiva circulando 5 a cada 15 minutos durante o dia e 10 minutos a cada 3 horas durante a noite. Para a produção de salsa em sistema hidropônico foram utilizadas bancadas dispostas em arranjo triangular, compostas por canos de polietileno específicos para hidroponia, medindo $7 \mathrm{~m}$ de comprimento, $1,70 \mathrm{~m}$ de altura e declividade a $8 \%$, apresentando perfurações espaçados em $24 \mathrm{~cm}$ entre plantas e bancadas.

Já o sistema semi-hidropônico, composto por seixo, substrato inerte (areia) e canos de polietileno (situados entre as linhas para distribuição da solução nutritiva), foi utilizado um canteiro coberto por plástico branco, medindo 4; 1,5, 1,10 e $2 \mathrm{~m}$ de comprimento, largura, altura e pé direito (figura 3 ), respectivamente, na qual as plantas foram inseridas em arranjo triangular com distância de $24 \mathrm{~cm}$ entre plantas e linhas.

Realizada no dia 25 de abril de 2019, a semeadura foi realizada em esponja fenólica, contendo 345 células, primeiramente umedecidas com água e posteriormente inseridas por intermédio de uma semeadora especifica, pós este processo, a bandeja foi inserida em uma estrutura fechada para que houvesse a germinação.

No dia primeiro de maio foi dado o início do processo de germinação e seis dias depois, praticamente todas as plantas já estavam germinadas, posteriormente a bandeja foi inserida na área de maternidade da estufa. No dia 22 de maio de 2019 foi realizado o transplante das mudas para seus respectivos sistemas, logo, metade das mudas foram transplantadas para os canais de cultivo hidropônico e metade para o substrato inerte da semi-hidroponia

Neste experimento, a extração do material para análise ocorreu em duas colheitas, estas ocorreram nos dias 20 de junho e 03 de julho de 2019, os procedimentos aplicados a ambas foram idênticos, evitando assim, interferência nos dados avaliados.

O delineamento aplicado foi o inteiramente casualizado (DIC) em esquema fatorial $2 \times 2$, sendo dois sistemas de cultivo (hidropônico e semi-hidropônico) e duas colheitas, contendo seis repetições. Cada repetição foi composta por um maço e cada maço foi composto por plantas provenientes de quatro células. O primeiro parâmetro a ser catalogado foi o teor de clorofila ( $A, B$ e Total), este foi conduzido antes do processo da colheita, com auxílio do aparelho ClorofiLOG-CFL1030, na qual foram medidas três folhas por célula.

Após a medição, as plantas eram cortadas com uma tesoura, incluídas aos seus respectivos maços devidamente amarrados, adicionadas em sacos plásticos e por fim identificadas, de 1 a 6 . Cada maço foi composto por plantas provenientes de 4 células, logo, foram coletados 12 pontos por repetição, o que equivale a 72 pontos por sistema de cultivo, no total, 144 pontos por colheita (Plantas provenientes de 48 células).

Após as coletas em campo, as plantas foram transportadas nos sacos plásticos para o laboratório multifuncional da Universidade Federal Rural da Amazônia (UFRA), campus Paragominas, onde foram 
realizadas as seguintes catalogações: número de folhas, peso de massa fresca, largura, comprimento e dados para o auxílio do cálculo de área foliar.

O primeiro parâmetro catalogado em laboratório foi o número de folhas, onde foram contadas manualmente todas as folhas, em seguida, com o auxílio de uma balança de precisão, as plantas foram pesadas por maço para obtenção do peso de massa fresca, pós pesagem, foram selecionadas ao acaso 10 folhas por repetição para medição de largura e comprimento, tal procedimento foi realizado por meio de um paquímetro digital.

Para o cálculo de área foliar, as 10 folhas selecionadas passaram por um processo de extração de uma circunferência de $5 \mathrm{~mm}$, totalizando 3 circunferências por folhas, 30 por maço e 180 por sistema de cultivo. Em seguida, as mesmas foram pesadas, bem como as folhas sem a circunferência. Por fim, as extrações foram adicionadas em sacos Kraft, identificadas e adicionadas na estufa a 60 드 por um período de três dias, para que houvesse total remoção da umidade. Pós este período, a massa seca foi pesada.

Ressaltando que todos os parâmetros foram catalogados igualitariamente para os dois sistemas de cultivo e colheitas. De posse dos dados, procedeu-se a análise de variância e as médias foram comparadas pelo teste de Tukey a 5\% de probabilidade, utilizando o programa estatístico Sisvar (FERREIRA, 2000).

\section{RESULTADOS E DISCUSSÃO}

De acordo com os dados obtidos, evidenciados na tabela 1, foi verificado uma interação significativa (**) para o sistema (semi-hidropônico e hidropônico) e colheita (primeira e segunda) nos seguintes parâmetros: número de folhas, peso de massa fresca e seca, área foliar e produtividade. Constatou-se efeito significativo, tanto para sistema como para colheita, em quatro dos cinco parâmetros avaliados, sendo a área foliar o parâmetro classificado como não significativo (NS). Diante destes dados, foi efetuado o desdobramento para verificar qual fator interferiu no resultado, sistema ou colheita.

Com relação ao número de folhas da cultura da salsa, o desdobramento dos sistemas dentro da colheita evidenciou uma diferença significativa $(p<0,05)$ para a primeira colheita, na qual o sistema hidropônico se destaca apresentando uma média equivalente a 227,16, já para segunda colheita, os resultados apontam indiferença significativa $(p>0,05)$ (Tabela 1$)$.

Contudo, no desdobramento da colheita dentro do sistema, tanto para a semi-hidroponia como para a hidroponia, as médias diferem estatisticamente $(p<0,05)$ e são superiores para a segunda colheita, apresentando valores de 284,33 e 278,33 , respectivamente (Tabela 1 ).

O parâmetro número de folhas é um fator de elevado interesse comercial, pois quanto maior o número de folhas, maior será a matéria fresca, resultando assim em alta produtividade, e para corroborar com esta afirmação, analisa-se a tabela 1 e verifica-se que a média que mais se destaca com relação ao número de folhas é a de cultivo hidropônico em sua segunda colheita, por consequência disto a massa fresca e produtividade também apresentam as melhores médias.

Um estudo realizado por Santos (2002), cultivando salsa, cebolinha e alfavaca em hidroponia, com concentrações de 50; 75; 100 e 125\% observou que a salsa foi a hortaliça que obteve os melhores resultados 
com relação aos parâmetros de altura, massa fresca e número de folhas, próximo a concentração de 100\% da solução proposta por Furlani et al. (1999).

Tabela 1: Médias dos parâmetros analisados nos sistemas de cultivo da salsa, em duas colheitas consecutivas.

\begin{tabular}{|c|c|c|c|c|c|}
\hline Sistema & № de folhas & Massa fresca (g) & Massa seca (g) & Área foliar $\left(\mathrm{mm}^{2}\right)$ & $\begin{array}{l}\text { Produtividade } \\
\text { (g planta-1) }\end{array}$ \\
\hline \multicolumn{6}{|l|}{ 1a colheita } \\
\hline Semi-hidropônico & $196,00 \mathrm{bB}$ & $27,18 \mathrm{bB}$ & $5,32 \mathrm{bB}$ & $49,79 \mathrm{bB}$ & $108,74 \mathrm{bB}$ \\
\hline Hidropônico & $227,16 \mathrm{aB}$ & $35,90 \mathrm{aB}$ & 7,15 aA & 65,47 aA & 143,60 aA \\
\hline \multicolumn{6}{|l|}{ 2a colheita } \\
\hline Semi-hidropônico & $284,33 \mathrm{bA}$ & $41,14 \mathrm{aB}$ & $8,73 \mathrm{aA}$ & $61,60 \mathrm{aB}$ & $164,55 \mathrm{aA}$ \\
\hline Hidropônico & $278,33 \mathrm{bA}$ & $27,46 \mathrm{bB}$ & $4,57 \mathrm{bB}$ & $41,86 \mathrm{bB}$ & $109,85 \mathrm{bB}$ \\
\hline Sistema & $* *$ & $* *$ & $* *$ & NS & $* *$ \\
\hline Colheita & $* *$ & $* *$ & $* *$ & NS & $* *$ \\
\hline Sistema x Colheita & $* *$ & $* *$ & $* *$ & $* *$ & $* *$ \\
\hline CV \% & 2,43 & 8,65 & 5,37 & 19,71 & 8,64 \\
\hline
\end{tabular}

*Letras minúsculas comparam médias do sistema dentro da colheita. Letras maiúsculas comparam médias da colheita dentro de cada sistema. Médias seguidas das mesmas letras na coluna não diferem entre si pelo Teste de Tukey a $5 \%$ de probabilidade. Fonte: Elaboração própria.

Para os parâmetros ligados ao peso dos maços, ou seja, massa fresca e massa seca, as médias diferiram entre si $(p<0,05)$ no desdobramento do sistema dentro de cada colheita em ambos os sistemas de cultivos analisados, na qual o sistema hidropônico se sobressai em relação ao semi-hidropônico em ambos os pesos (fresco e seco) para a colheita de número 1, com valores de 35,90 g e 7,15 g, respectivamente. Contudo, quando se analisa a segunda colheita, ocorre uma inversão, e o sistema semi-hidropônico ganha destaque para ambos os pesos, com médias de 41,14 g e 8,73 g, nesta ordem (Tabela 1).

Luz et al. (2012), avaliando a produção hidropônica de coentro e salsa crespa sob diferentes concentrações de solução nutritiva obtiveram valor máximo de massa fresca e seca em salsa hidropônica de 10,93 e 1,16 g planta $^{-1}$, respectivamente, tais dados são inferiores se comparados com os encontrados neste trabalho, tanto no sistema hidropônico como no sistema semi-hidropônico.

No desdobramento da colheita dentro de cada sistema, as médias de massa fresca das plantas de salsa obtiveram diferença não significativa $(p>0,05)$ nas duas colheitas. Já para o parâmetro massa seca, as médias apresentaram diferença significativa $(p<0,05)$ em ambas, se destacando a segunda colheita para a semi-hidroponia $(8,73 \mathrm{~g})$ e a primeira colheita para a hidroponia $(7,15 \mathrm{~g})$, como ilustrado na tabela 1 , tal fenômeno pode ser justificado devido ao número de folhas terem sido maior para os sistemas nestas respectivas colheitas, como mencionado anteriormente.

Observou-se que para a área foliar, no desdobramento do sistema dentro da colheita, as médias diferiram entre si $(p<0,05)$ nas duas colheitas, apresentando médias superiores o sistema hidropônico para a primeira colheita, com $65,47 \mathrm{~mm}^{2}$ e o semi-hidropônico na segunda colheita com $61,60 \mathrm{~mm}^{2}$ (Tabela 1).

No desdobramento da colheita dentro de cada sistema, o sistema semi-hidropônico não diferiu nas colheitas analisadas, já a hidroponia diferiu e apresentou melhores resultados na primeira colheita, apresentando uma média equivalente a $65,47 \mathrm{~mm}^{2}$ (Tabela 1 ).

Segundo Taiz et al. (2017) a área foliar tem sua importância por ser uma variável de crescimento indicativa da produtividade, visto que o processo fotossintético depende da interceptação da energia 
luminosa e sua conversão em energia química, sendo este um processo que ocorre diretamente na folha.

Em termos de produtividade, no desdobramento do sistema dentro da colheita, houve diferença significativa $(p<0,05)$ de médias para ambas as colheitas, sendo a salsa de sistema hidropônico mais produtiva apenas na primeira colheita $\left(143,60 \mathrm{~g} \mathrm{planta}^{-1}\right)$, pois, quando se analisa a segunda colheita, verificase uma produtividade maior para o sistema semi-hidropônico $\left(164,55 \mathrm{~g} \mathrm{planta}^{-1}\right)$, conforme mostra a tabela 1. Fazendo uma análise da colheita em cada sistema, observa-se que para o cultivo semi-hidropônico, a colheita de número 2 difere e ganha notoriedade $\left(164,55 \mathrm{~g}\right.$ planta $\left.^{-1}\right)$, enquanto que para o cultivo hidropônico, a colheita de número 1 se sobressai $\left(143,60 \mathrm{~g} \mathrm{planta}^{-1}\right)$, como visto na tabela 1.

Na Tabela 2, estão presentes as médias de largura, comprimento e a razão de peso foliar (RPF), foi verificado uma interação significativa para os sistemas e colheitas nos parâmetros largura e comprimento, para o sistema não houve diferença significativa $(p>0,05)$ e para a colheita houve efeito significativo para os todos os parâmetros.

Tabela 2: Médias dos parâmetros foliares analisados nos sistemas de cultivo da salsa, em duas colheitas consecutivas.

\begin{tabular}{|c|c|c|c|}
\hline \multirow{2}{*}{ Sistema } & Largura (mm) & Comprimento (mm) & RPF \\
\hline & \multicolumn{3}{|l|}{ 1a colheita } \\
\hline Semi-hidropônico & $50,87 \mathrm{aA}$ & $38,15 \mathrm{bB}$ & $0,04 \mathrm{bA}$ \\
\hline \multirow[t]{2}{*}{ Hidropônico } & $41,46 \mathrm{bB}$ & $42,13 \mathrm{bA}$ & $0,05 \mathrm{bA}$ \\
\hline & \multicolumn{3}{|l|}{ 2a colheita } \\
\hline Semi-hidropônico & $44,58 \mathrm{aB}$ & $31,52 \mathrm{bB}$ & $0,03 \mathrm{bB}$ \\
\hline Hidropônico & $33,38 \mathrm{bB}$ & $38,65 \mathrm{aB}$ & $0,03 \mathrm{bB}$ \\
\hline Sistema & NS & NS & NS \\
\hline Colheita & $* *$ & $* *$ & $* *$ \\
\hline Sistema $\times$ Colheita & $* *$ & $* *$ & NS \\
\hline CV \% & 9,16 & 10,52 & 25,46 \\
\hline
\end{tabular}

* Letras minúsculas comparam médias do sistema dentro da colheita. Letras maiúsculas comparam médias da colheita dentro de cada sistema. Médias seguidas das mesmas letras na coluna não diferem entre si pelo Teste de Tukey a 5\% de probabilidade; RPF: Razão de peso foliar.

O parâmetro largura das folhas de salsa, no desdobramento de sistema dentro da colheita, apresentou diferença significativa $(p<0,05)$ nas duas colheitas, na qual a maior média foi atribuída ao semihidropônico $(50,87 ; 44,58 \mathrm{~mm})$ na colheita 1 e 2, respectivamente. No desdobramento da colheita dentro de cada sistema, o sistema semi-hidropônico diferiu nas colheitas analisadas com média superior para a primeira colheita (50,87 mm), já a hidroponia não apresentou diferença estatisticamente (Tabela 2).

Analisando o comprimento das folhas desta hortaliça, observou-se que as médias não diferiram entre si $(p>0,05)$ no desdobramento de sistemas dentro colheita, para a colheita 1 , já para a colheita 2 , o cultivo hidropônico apresentou os melhores resultados $(38,65 \mathrm{~mm})$. No desdobramento da colheita dentro de cada sistema, observa-se indiferença para o cultivo semi-hidropônico e destaque para a primeira colheita do cultivo hidropônico (Tabela 2).

Para a razão de peso foliar (RPF), observou-se apenas diferença estatística com relação ao desdobramento da colheita dentro de cada sistema, na qual a primeira colheita apresenta as melhores médias, tanto para o cultivo hidropônico, como para o semi-hidropônico.

Não foi encontrado trabalhos diretamente relacionados com a comparação destes sistemas de cultivo para a cultura da salsa, principalmente quando se trata de semi-hidroponia, percebe-se que existe 
uma insuficiência em dados que auxiliem na corroboração, caracterização e diferenciação dos tipos de sistemas de cultivo e colheitas da salsa.

De acordo com os dados obtidos para os teores de clorofila, evidenciados na tabela 3 , foi verificado uma interação não significativa (NS) para o sistema (semi-hidropônico e hidropônico) e colheita (primeira e segunda) nos seguintes parâmetros: Clorofila A, B e Total.

Tabela 3: Médias de clorofila de plantas de salsa em sistemas de cultivo hidropônico e semi-hidropônico, em Paragominas-PA.

\begin{tabular}{|c|c|c|c|}
\hline \multirow{2}{*}{ Sistema } & \multicolumn{3}{|l|}{ Clorofila } \\
\hline & A & B & Total \\
\hline & \multicolumn{3}{|l|}{ 1a colheita } \\
\hline Semi-hidropônico & $23,59 \mathrm{bB}$ & $8,47 \mathrm{aA}$ & $35,69 a B$ \\
\hline \multirow[t]{2}{*}{ Hidropônico } & $25,42 \mathrm{bB}$ & $6,87 \mathrm{bB}$ & $32,55 \mathrm{bB}$ \\
\hline & \multicolumn{3}{|l|}{ 2a colheita } \\
\hline Semi-hidropônico & 30,59 bA & $7,61 \mathrm{bB}$ & 39,09 aA \\
\hline Hidropônico & 33,71 aA & $8,38 \mathrm{bB}$ & $35,62 \mathrm{bA}$ \\
\hline Sistema & $* *$ & $* *$ & $* *$ \\
\hline Colheita & $* *$ & NS & $* *$ \\
\hline Sistema x Colheita & NS & NS & NS \\
\hline CV \% & 14,92 & 17,54 & 6,55 \\
\hline
\end{tabular}

* Letras minúsculas comparam médias do sistema dentro da colheita. Letras maiúsculas comparam médias da colheita dentro de cada sistema. Médias seguidas das mesmas letras na coluna não diferem entre si pelo Teste de Tukey a 5\% de probabilidade.

Observa-se que para sistema, ocorreu uma interação significativa para todos os parâmetros, enquanto que para colheita, apenas a clorofila B não apresentou tal interação.

Analisando a clorofila A na primeira colheita, o desdobramento não aponta diferença significativa ( $p$ $>0,05)$, já para a segunda colheita a hidroponia se destaca $(33,71)$, no desdobramento da colheita dentro do sistema, observa-se que ambas apresentam diferença significativa $(p<0,05)$, sendo a 2 a colheita com melhor resultado para ambos os sistemas. Segundo Casais et al. (2020) uma maior quantidade de folhas nas plantas cultivadas em sistemas hidropônico e semi-hidropônico pode explicar uma maior capacidade de absorção de radiação solar, ampliando assim a faixa de absorção de luz para a clorofila $(a)$. Os pigmentos fotossintéticos presentes e a sua abundância variam de acordo com a espécie. A clorofila A está presente em todos os organismos que realizam fotossíntese oxigênica, este é o pigmento utilizado para realizar a fotoquímica (o estágio inicial no processo fotossintético), enquanto que os demais pigmentos auxiliam na absorção de luz e na transferência da energia radiante para os centros de reação, sendo assim chamados de pigmentos acessórios (SILVA et al., 2019).

Para a clorofila B (Tabela 03), observa-se o inverso no desdobramento do sistema dentro da colheita, ou seja, segunda colheita não aponta diferença estatística $(p>0,05)$, e a primeira colheita aponta com destaque para a semi-hidroponia $(8,47)$. Segundo Borges et al. (2020) os teores de clorofila A e B nas plantas em sistema hidropônico está relacionado com a carência de nutrientes, o que diminui a taxa fotossintética nas folhas, isso, segundo os autores é muitas vezes, em função da solução nutritiva usada no sistema.

Com relação a clorofila total (Tabela 3$)$, observa-se diferença significativa $(p<0,05)$ em ambos os desdobramentos, para ambas as colheitas, a melhor média está ligada ao sistema semi-hidropônico (35,69 e $39,09)$, quando se análise o desdobramento da colheita dentro do sistema, verifica-se melhor média para a 
segunda colheita.

Diante do exposto, verifica-se que no geral a semi-hidroponia apresentou os melhores resultados de clorofila A, B e Total, com melhor média para a segunda colheita. Wunderlich et al. (2020) afirma que as clorofilas são consideradas os pigmentos naturais de maior abundância nos vegetais, está presente nos cloroplastos das folhas e em outros tecidos vegetais. Tem-se conhecimento de que este parâmetro apresenta uma importância imensurável, por ser responsável pela captação de luz, e por meio do processo da fotossíntese os mesmos produzem seu alimento, logo, são essenciais para a manutenção do oxigênio disponível no planeta.

\section{CONCLUSÕES}

Em termos de produtividade, a salsa apresenta melhor resultado no sistema semi-hidropônico se colhido após a rebrotação, ou seja, segunda colheita. Se o cultivo for em hidroponia, a maior produtividade se dará na primeira colheita. No geral, a salsa hidropônica apresentou melhores resultados, quando comparado ao sistema de cultivo no semi-hidropônico, na maior parte dos parâmetros analisados. A clorofila (A, B e Total) no sistema semi hidropônico foi superior se comparado com sistema hidropônico, com melhor média para a segunda colheita.

\section{REFERÊNCIAS}

BORGES, L. S.; ARAÚJO, J. M.; CASAIS, L. K. N.; ARAÚJO, L. A.; SOUZA, F. C.; SANTOS, N. F. A.; MELO, M. R. S.; ALVES, G. A. R.. Sintomatologia foliar de nutrientes em plantas de Jambu hidropônica, produzidas em propriedade familiar. In: SANTOS, C. A.. Pesquisa e inovação em horticultura. Maringá: Uniedusul, 2020. p.28-38.

BRONDANI, A.. Hortifruti é responsável por 13 milhões de empregos no país, diz relatório. 2018.

CASAIS, L. K. N.; BORGES, L. S.; MEDEIROS, M. B. C. L.; SOUZA, M. E.; SOARES, D. S.. Índices morfofisiológicos e clorofila de Hortelã-Pimenta cultivadas sob diferentes sistemas de cultivos. Revista Ibero-Americana de Ciências Ambientais, v.11, n.3, 2020.

COSTA, M. T. S.. Ensaio de competição entre cultivares de salsa (Petroselinum crispum) em ambiente aberto. Monografia (Bacharelado em Agronomia) - Universidade de Brasília, Brasília, 2017.

FAPESPA. Estatísticas Municipais Paraenses: Paragominas. Belém: Diretoria de Estatística e de Tecnologia e Gestão da Informação, 2016.

FERREIRA, D. F.. Análises estatísticas por meio do Sisvar para Windows versão 4.0. In: REUNIÃO ANUAL DA REGIÃO BRASILEIRA DA SOCIEDADE INTERNACIONAL DE BIOMETRIA, 45. Anais. São Carlos: UFSCar, 2000. p.255-258.

FURLANI, P. R.; SILVEIRA, L. C. P.; BOLONHEZI, D.; FAQUIN, V.. Cultivo hidropônico de plantas. Campinas: Instituto Agronômico, 1999.
HOEPERS, L. M. L.. Crescimento de cultivares de salsa (Petroselinum crispum) em condições de sombreamento e a pleno sol. Dissertação (Mestrado em Agronomia) Universidade Estadual do Oeste do Paraná, Marechal Cândido Rondon, 2017.

LUZ, J. M. Q.; ANDRADE, L. V.; DIAS, F. F.; SILVA, M. A. D.; HABER, L. L.; OLIVEIRA, R. C.. Produção hidropônica de coentro e salsa crespa sob concentrações de solução nutritiva e posições das plantas nos perfis hidropônicos. Bioscience Journal, v.28, n.4, 2012.

MARTINS, J. B.; SANTOS JÚNIOR, J. A.; BARTUSCH, V. P.; GHEYI, H. R.; BEZERRA NETO, E.; SILVA, M. M.. Water relations in parsley plants cultivated in brackish nutrient solutions of different cationic natures. Revista brasileira de Engenharia Agrícola e Ambiental, Campina Grande, v.23, n.9, p.662-668, 2019.

SABINO, F.. Ervas e especiarias na cozinha italiana. Monografia (Bacharelado em gastronomia) - Faculdade de Tecnologia Estácio, Belo Horizonte, 2010.

SANTOS, J. E.. Cultivo hidropônico de Allium fistulosum (cebolinha), Ocimum basilicum (alfavaca), e Petroselinum crispum Nym. (Salsa) em diferentes concentrações de solução nutritiva. Dissertação (Mestrado) - Universidade Federal de Uberlândia, Uberlândia, 2002.

SILVA, P. F.; MATOS, R. M.; PEREIRA, M. O.; BORGES, V. E.; DANTAS NETO, J.; LIMA, V. L. A.. Chlorophyll content in beet cv. Early Wonder under nitrogen fertilization. Rev. Ceres, Viçosa, v.66, n.6, p.460-469, 2019. 
TAIZ, L.; ZEIGER, E.; MOLLER, I. M.; MURPHY, A.. Fisiologia e desenvolvimento vegetal. 6 ed. Porto Alegre: Artmed, 2017.

WUNDERLICH, A. L. M.; AZEVEDO, S. C. S. F.; YAMADA, L. A.; BATAGLINI, C.; PREVIATE, C.; CAMPANHOLI, K. S. S.; PEREIRA, P. C. S.; CAETANO, W.; KAPLUM, V.; NAKAMURA, C. V.; NAKANISHI, A. B. S.; COMAR, J. F.; PEDROSA, M. M. D.; GODOI, V. A. F.. Chlorophyll treatment combined with photostimulation increases glycolysis and decreases oxidative stress in the liver of type 1 diabetic rats. Brazilian Journal of Medical and Biological Research, Ribeirão Preto, v.53, n.1, 2020.

ZEN, H. D.; BRANDÃO, J. B.. Competitividade da produção hidropônica de hortaliças folhosas no Brasil. Revista de Política Agrícola, v.28, n.1, p.115, 2019.

A CBPC - Companhia Brasileira de Produção Científica (CNPJ: 11.221.422/0001-03) detém os direitos materiais desta publicação. Os direitos referem-se à publicação do trabalho em qualquer parte do mundo, incluindo os direitos às renovações, expansões e disseminações da contribuição, bem como outros direitos subsidiários. Todos os trabalhos publicados eletronicamente poderão posteriormente ser publicados em coletâneas impressas sob coordenação da Sustenere Publishing, da Companhia Brasileira de Produção Científica e seus parceiros autorizados. Os (as) autores (as) preservam os direitos autorais, mas não têm permissão para a publicação da contribuição em outro meio, impresso ou digital, em português ou em tradução. 